\title{
Miscellany
}

\section{Kurt-Schneider Scientific Award}

This prize for exceptional scientific achievements is sponsored by Janssen-Cilag GmbH Germany, endowed with $10000 \mathrm{DM}$ and will be awarded at the 13th Weibenauer Schizophrenia Symposium in May 2000. The aim of the prize is to encourage psychiatric research, especially in schizophrenia (clinical psychopathology, diagnostics, prevention, therapy and rehabilitation), including basic research. Entry papers (seven-fold, with a short summary) should be sent to the Board of Trustees no later than 15 October 1999, c/o the Chairman, Professor Gerd Huber, UniversitaetsNervenklinik, D-53105 Bonn (Venusberg), Germany (telephone: 49228287 5725; fax: 49 2283228 83).

\section{New publications}

What Stress! The Once in a Lifetime Programme That Will Help you Control Stress in Your Workplace and What Stress in Primary Care!
The Once in a Lifetime Programme that Will Help you Control Stress in Your Practice are the titles of two new books by Ruth Chambers and Martin Davies, published by the Royal College of General Practitioners (RCGP). Easy to use and fully interactive, both books have two main parts, teaching readers first how to understand and control their own stress levels, then how to transfer that knowledge to their working colleagues. What Stress in Primary Carel is different because the authors have special insight into the particular problems experienced by general practitioners and practice staff. Each book is priced at $£ 18.00$ (RCGP members) and £19.99 (non-members) inclusive of postage and packaging. However, if both books are purchased they can be obtained for a special price of $\$ 33.00$ (RCGP members) or $£ 36.00$ (non-members). For further information or to order copies of these publications please contact the RCGP Sales Office, 14 Princes Gate, Hyde Park, London SW7 1PU (telephone: 0171823 9698; e-mail: sales@rcgp.org.uk).

\section{A report from The Royal College of Psychiatrists Patient Advocacy Council Report CR74}

This report, produced by a working group of the Patients' and Carers' Liaison Group, updates the College's policy on issues relating to patient advocacy. It summarises definitions of advocacy, with emphasis on the role of the advocate in helping patients speak for themselves. The advantages of well organised advocacy services are listed, and it is suggested that certain patient groups, such as those from ethnic minorities, benefit especially from their presence. Special considerations apply when planning advocacy services for people with learning disabilities, children and adolescents and the elderly, and in forensic work. Training of advocates is essential, and problems arise when advocates are untrained or when psychiatrists and advocates allow entrenched, adversarial situations to arise. Unfortunately, advocacy services are patchily developed and poorly researched. Psychiatrists are encouraged to promote advocacy schemes and to ensure that psychiatrists in training gain experience of working with them.

\section{February 1999, £5.00}

Information on all College publications is available on the Internet at: http://www.rcpsych.ac.uk Royal College of Psychiatrists, Book Sales Department, 17 Belgrave Square, London SW1X 8PG Tel: 01712352351 extension 146, Fax: 01712451231 